\title{
Method for diagnosing the ICE cylinder-piston group in the combustion chamber in the mode of cranking the engine crankshaft
}

\section{Alexandr Gritsenko}

South Ural State University (National Research University): Uzno-Ural'skij gosudarstvennyj universitet Vladimir Shepelev ( $\square$ shepelevvd@susu.ru )

South Ural State University https://orcid.org/0000-0002-1143-2031

\section{Sergey Baryshnikov}

Institut agroinzenerii Uzno-Ural'skogo gosudarstvennogo agrarnogo universiteta

\section{Original Article}

Keywords: cylinder-piston group, diagnostic, in-place oscillographic method, engine faults

Posted Date: October 12th, 2020

DOI: https://doi.org/10.21203/rs.3.rs-88807/v1

License: (c) (1) This work is licensed under a Creative Commons Attribution 4.0 International License.

Read Full License 


\title{
Method for diagnosing the ICE cylinder-piston group in the com-
}

\section{bustion chamber in the mode of cranking the engine crankshaft}

\author{
Alexandr Gritsenko ${ }^{1,2}$, Vladimir Shepelev ${ }^{1,3^{*}}$, Sergey Baryshnikov ${ }^{2}$
}

${ }^{1}$ South Ural State University, Chelyabinsk, Russia

${ }^{2}$ South Ural State Agrarian University, Chelyabinsk, Russia

${ }^{3}$ Silkway International University, Shymkent, Kazakhstan

*Corresponding author: Vladimir Shepelev, email: shepelevvd@ susu.ru

Abstract. To increase the diagnostic efficiency, significantly reduce the unproductive time, and mainly increase the reliability and accuracy, we propose a new method and tools implementing it - an oscillographic method for monitoring the pressure and phase parameters during the dynamic change in the operating parameters. The proposed work is aimed at improving the internal combustion engine (ICE) performance by timely diagnosing the cylinder-piston group (CPG) and its maintenance based on the diagnostic results. The scientific novelty of the work lies in the establishment of the interconnection of the CPG parameters obtained in the test modes of the ICE operation, allowing us to justify the diagnostic modes and their limiting values; the development of diagnostic methods and tools allowing us to justify the test modes for diagnosing the ICE CPG; the experimental data, which revealed that the instantaneous pressure signal in the combustion chamber is a sensitive diagnostic sign, which reflects the technical condition of the ICE CPG and its elements; the results of the experimental studies of diagnosing the ICE CPG in test modes. The results of the experimental work were compared with the results of theoretical modeling, the con- 
vergence between them was $97-99 \%$. The production validation of the new method demonstrated the reliability within $0.92-0.97$.

Keywords: cylinder-piston group, diagnostic, in-place oscillographic method, engine faults.

\section{Introduction}

We have established that the lack of diagnostic tools reliably determining the technical condition of the CPG, together with the generalized costs for restoring components and mechanisms (connecting rod and piston group, cylinder heads, valve of the gas distribution mechanism, cylinder head gasket) can reach $2300 €$ depending on the car model. A critical approach to determining the disadvantages and advantages of various CPG diagnosing means allowed us to determine the main disadvantage, which is the prohibitively long time of preparatory and final operations, low reliability, and unacceptable sensitivity. The above conclusion applies to the cylinder-piston group and rings. The purpose of the work is to develop an in-place oscillographic method for monitoring the pressure and phase parameters during the dynamic changes in the operating parameters.

As a result of analyzing the statistics of the number of ICE system failures, it has been established that the main reason for the decrease in reliability is the violation of the maintenance and repair regulations, as well as the operating conditions $[1,2,3]$. The most loaded part of the engine is the ICE CPG, which accounts for $30 \%$ of failures of the total number of engine faults. In turn, the wear of the piston group, any seal 
failure of the combustion chambers, and the displacement of the GDM phases leads to significant emissions of exhaust gases into the atmosphere, as well as to an increase in the fuel and oil consumption, and a decrease in road traffic safety. In the operating practice, wear is formed smoothly provided that all the technical conditions are satisfied. However, in practice, ICEs are operated in the most severe conditions: high temperature, gaseous environment, high cyclic loads $[4,5,6]$. Under these conditions, the law of the change in the technical condition takes an exponential form. Failures occur instantly, and it is most important at this moment to assess the condition [7, 8].

The issues of technical diagnostics of the engine CPG and GDM have been studied by some researchers.

Gasparjans et al. [9] focused on the determination of the current condition of one of the most loaded elements of the cylinder-piston group of the vessel diesel engines - the piston ring. The piston ring with a gap is placed in a vertical position, it is fixed at a single point symmetrically to the gap. Its both half-segments form a fork. At the first stage of the diagnostics the parameters of the left and right segments are compared with each other. A ring without defects has similar parameters of the segments. The second stage of the diagnostics is the comparison of the obtained results with reference values that are average results of measurements of some serviceable rings without defects.

Authors [10] examined an alternative method, which consists in analyzing a signal obtained using a current-voltage converter, the output of which is proportional to the first-order derivative of the measured pressure. The researchers propose new dimensionless criteria defined in the analysis of such a signal. It has been theoretically 
and experimentally shown that, using the proposed criteria, it is possible to simply and reliably diagnose the wear of a cylinder-piston group and deviations in the adjustment of the fuel injection advance angle.

A mathematical model of the formation of the metal volume worn from rubbing parts of a diesel in engine oil is presented in [11]. The difficulty lies in assessing, based on the analysis of current values of wear debris concentration, the amount of metal worn from parts, since external factors influence the process of concentration formation.

Also these authors presented results of application of the artificial neural networks for diesel diagnostics based on the results of a spectral analysis of engine oil. Artificial neural network has been created and trained to identify pre-failure condition of the details of cylinder-piston group and crank-And-rod mechanism using the diesel locomotive 49 as an example [12].

In [13] the basic opportunity of use of the radio wave method for diagnostics of a condition of internal combustion engines is shown. Use of the offered method allows differentiating without disassembly of the engine malfunction cylinder-piston groups and making decision on necessity of repair or cleaning of cylinders of the engine from products of combustion.

The studies of the evaluation of combustion chamber leakage of four stroke marine diesel engines by using a Pneumatic Indicator are carried out by Mollah [14]. Author describes the methodology to develop the performance limits of the combustion chamber leakage of marine diesel engine and the method of evaluating the condition of diesel engines. 
ment, the authors [15] measure simultaneously along two coordinates: in the plane of the ring - the radial oscillations; and in the axial plane - perpendicular to the plane of the ring. The suggested method of the piston ring condition monitoring refers to the non-destructive methods.

Gutiérrez et al. constructed a thermodynamic zero-dimensional model of a 6cylinder marine diesel engine and developed methodology to detect, identify and quantify faults of its components [16]. A methodology has been implemented that allows simulating four types of faults, based on the developed thermodynamic model. The diagnostic model was based on parameter estimation using the LevenbergMarquardt method and results showed a high degree of confidence.

Methodology that can be used as a diagnostic tool to determine the compression condition of diesel engines is developed in [17]. An experimental investigation is conducted to examine the effect of the initial pressure at the inlet valve closure, the compression ratio and the blowby on the cylinder pressure trace. From analysis of the measured data, it is followed that each parameter has a different effect on the different parts of the compression pressure trace. It is possible to determine the compression condition of an engine cylinder based on the measured cylinder pressure trace.

Authors in [17] proposed a methodology for the analysis of wear in internal combustion engine valves, which is the result of the combined use of numerical and experimental techniques. The numerical solutions are obtained using a specialized Finite Element Method, where a mortar contact algorithm is used to model a flexibleflexible contact along with an adhesive wear law. 
The existing routine maintenance strategy presupposes maintenance and application diagnostics included in it [19]. As the circumstances require, the strategy is most often applied in cases of extreme wear. External diagnostic tools, which include compression testers, leak indicators, pneumatic testers, and flow meters, are used for the existing system of scheduled preventive maintenance and repair. Using the above diagnostic methods, the time of the preparatory work can be up to $90 \%$ of the total diagnostic process period $[14,16,20]$. At the same time, the accuracy and reliability remain at an unacceptably low level [21]. It is problematic to develop a new diagnostic method with low time-consuming preparatory and final works and increased reliability of the used diagnostic tools. All of the above requirements are satisfied by our proposed diagnostic method for monitoring the pressure value in the combustion chamber when the crankshaft is cranked by a starter $[5,6]$. The advantage of this method is the ease of installing the measuring devices, the high selectivity of a faulty component, short duration of the diagnostic process, high reliability, and accuracy.

\section{Theoretical research}

The main purpose of the theoretical research is to establish the relationship between the pressure parameters and phase parameters with the technical condition of the CPG in the dynamic mode of testing.

We will take the specifications of the widely used ZMZ-406 engine as a calculation basis and introduce the boundary conditions. The main condition for the initial state of the system will be the adiabatic compression process, which is an ideal process without any exchange with the atmosphere $[22,23]$. In the theory of thermodynamic 
140 calculations, such a system is called closed and used to simplify the calculation of the

141 ICE operating cycles $[24,25,26]$. In such an ideal system, the output parameters of the 142 operating cycle, pressure and phase, and temperature parameters are uniform in vol143 ume, and local drops and gradients are not taken into account in the calculations. In 144 fact, in real conditions, the main and accompanying processes seem to be more com145 plicated for theoretical calculations [27, 28]. At the initial calculation stage, we apply 146 the well-known formula:

$$
P V=\mu R T
$$

148 where $P$ is the pressure in the working chamber of the cylinder, $\mathrm{Pa} ; V$ is the volume of 149 compressed air, $\mathrm{mm}^{3} ; \mu$ is the molar mass of the air or fuel-air mixture depending on 150 the mode; $R$ is the universal gas constant, $\mathrm{J} / \mathrm{kg} ; T$ is the operating temperature of the 151 compression process in the cylinder, $\mathrm{K}$. Let us represent the condition for the implementation of the ideal adiabatic process, which has the form:

$$
P V^{k}=\text { const or } P_{1} v_{1}^{k}=P_{2} v_{2}^{k}
$$

155 where $k$ is the characteristic of the adiabatic process (equal to 1.4 for our variant).

157 using the formula known in the tractor industry:

$$
j=R_{c j}\left[(1-\cos \varphi)+\frac{\lambda}{4}(1-\cos 2 \varphi)\right]
$$


159 where $\varphi$ is the geometric angle characterizing the arc of the crankshaft rotation from 160 the zero value taken as the counting base, rad; $R_{c j}$ is the working radius of the crank161 shaft journal, $\mathrm{mm} ; \lambda$ is a parametric coefficient.

Let us calculate the dependence of the piston stroke on the crankshaft rotation angle when substituting the data into equation (3), which results in a graph shown in 164 Figure 1.

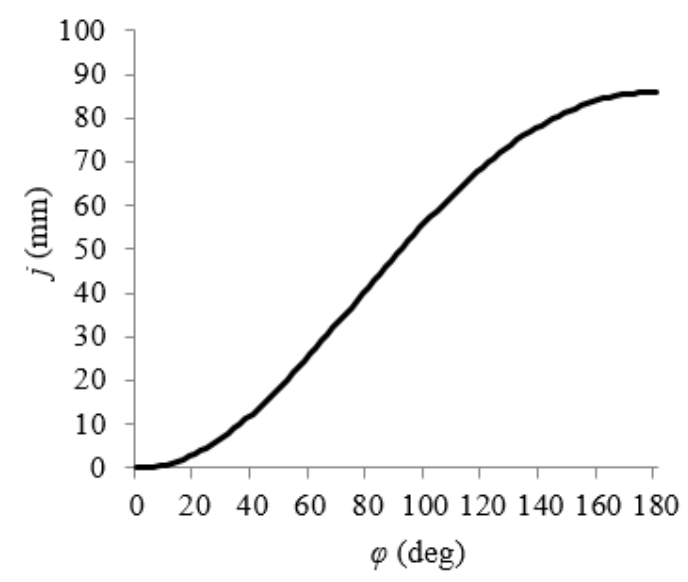

Figure 1. The calculated dependence of the working stroke of the piston value $j$ on the change in the engine crankshaft rotation angle $\varphi$.

An analysis of the data in Figure. 1 shows that at the point corresponding to 0 degrees, the piston stroke is 0 , and the maximum stroke value is reached at the point corresponding to 180 degrees.

Let us calculate an important characteristic considering the space occupied by the air in the cylinder, taking into account the working stroke of the piston, which can be presented in the form of the following expression:

$$
V_{2}=\left(V_{\text {work }}+V_{\text {c.c. }}\right)-j \cdot S_{\text {pist }}
$$



compression process, we make calculations according to equation (4), based on which 178 we obtain the dependence shown in Figure 2.

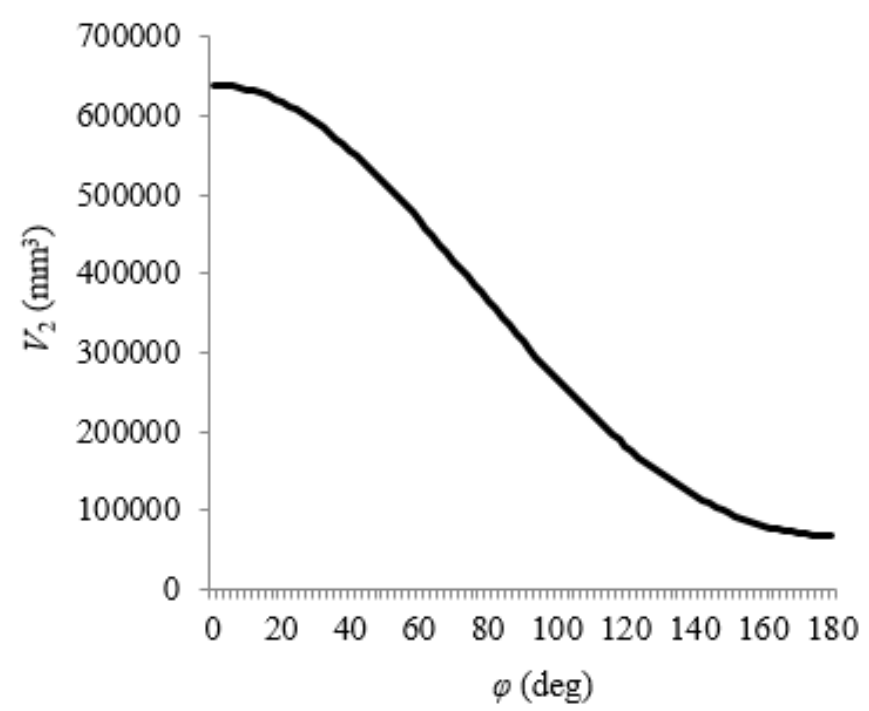

Figure 2. The operating characteristic of the change in volume in the space above the piston $V_{2}$ depending on the change in the ICE crankshaft rotation angle $\varphi$.

The calculation of the characteristic of the change in the volume in the space above the piston shown in Figure 2 indicates the typical minimum and maximum points, which correspond to the points of 180 and 0 degrees.

Let us use the ratio between the pressure and volume values, which results in the formula for calculating the pressure value in the combustion chamber $\left(P_{2}\right)$ depending on the variation of the working volume of the space above the piston:

$$
P_{2}=P_{1} \cdot\left(\frac{V_{1}}{V_{2}}\right)^{k}
$$

where $P_{1}$ is the pressure in the combustion chamber corresponding to the beginning of the compression stroke, Pa.

Taking into account the previous calculations and the operating parameters of the ZMZ-406 engine, we calculate the dynamics of the change in the pressure value in 
194 the combustion chamber according to equation (5), which results in a graphical de195 pendence shown in Figure 3.

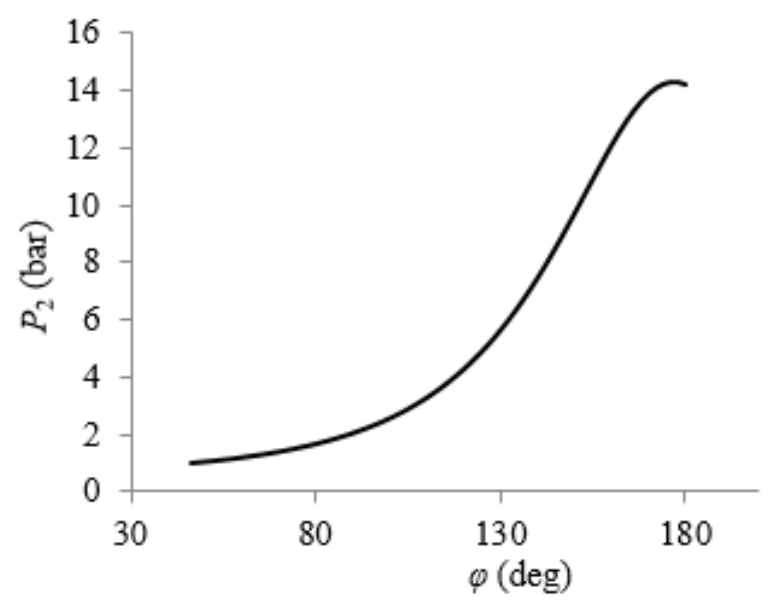

Figure 3. The dependence of the change in the pressure value in the combustion chamber $P_{2}$ on the change in the ICE crankshaft rotation angle $\varphi$.

The calculation results presented in the form of a graph in Figurer 3 show that the minimum pressure value corresponds to the range of $0-15$ degrees, and the maximum pressure value of 14.1 bar corresponds to the range of $175-180$ degrees.

The change in the parameters of the combustion chamber volume, piston stroke, and pressure at the end of the compression stroke cause an increase in the temperature parameters. Against this background, the ratio of the temperature and volumetric parameters is expressed through the adiabatic coefficient, which is presented in equation (6):

$$
T_{2}=T_{1} \cdot\left(\frac{V_{1}}{V_{2}}\right)^{k-1}
$$

where $T_{1}$ and $T_{2}$ are the initial and subsequent temperature in the compression volume (after 2 degrees of the crankshaft rotation) of the cylinder walls, ${ }^{\circ} \mathrm{C} ; V_{1}$ and $V_{2}$ are the working volume of the space above the piston at the initial moment corresponding to 0 
212 degrees of the ICE crankshaft rotation and the working volume of the space above the 213 piston at each subsequent discrete moment of time, $\mathrm{mm}^{3}$.

One of the calculation conditions is to assume that at the initial counting moment, the air temperature in the space above the piston is at the level $T_{1}=293^{\circ} \mathrm{K}$.

For further calculations of the pressure value $(Q)$ in the combustion chamber, taking into account heat transfer, we calculate the instantaneous amount of heat transferred by the air during compression to the cylinder head and the working walls of the combustion chamber, depending on the change in the ICE crankshaft rotation angle.

$$
Q=t \cdot \alpha_{a} \cdot F_{w} \cdot\left(\left(\frac{T_{1}+T_{2}}{2}\right)-293\right)
$$

where $t$ is the time of the engine crankshaft rotation at an angle $\varphi, \mathrm{s} ; \alpha_{a}$ is the air heat transfer coefficient, $\mathrm{W} / \mathrm{m}^{2} \cdot \mathrm{K} ; F_{w}$ is the area of the cylinder and combustion chamber walls, through which the heat is transferred, $\mathrm{mm}^{2}, F_{w}=F_{c w}+F_{c c}$;

The air heat transfer coefficient is a function of pressure and temperature in the cylinder and is determined by the following dependence:

$$
\alpha_{a}=0.475 \cdot \sqrt{T_{2} \cdot \mathrm{P}_{2}}
$$



for heat exchange, the pressure value of the compression stroke is determined from the

247

Figure 4. The dependence of the air heat transfer coefficient $\alpha_{a}$ on the air pressure in the combustion chamber $P_{2}$.

An analysis of Figure 4 shows that the maximum value of the heat transfer coefficient corresponds to a pressure of 12.5-13.0 bar.

After the heat is transferred to the cylinder walls, the air temperature in the cylinder is calculated by the following equation:

$$
T_{3}=T_{2}-\frac{Q}{m \cdot C_{v}}
$$

where $T_{3}$ is the air temperature in the cylinder when the heat is transferred to the cylinder walls, $\mathrm{K}$.

The heat exchange process is accompanied by the transfer of energy of the working fluid to the ICE elements [29, 30]. An analysis of the energy balance shows that some heat is lost, and the calculated pressure value at the end of the compression stroke and the temperature of the accompanying processes change significantly (deviating considerably from the ideal conditions). Taking into account the energy losses parametric ratio:

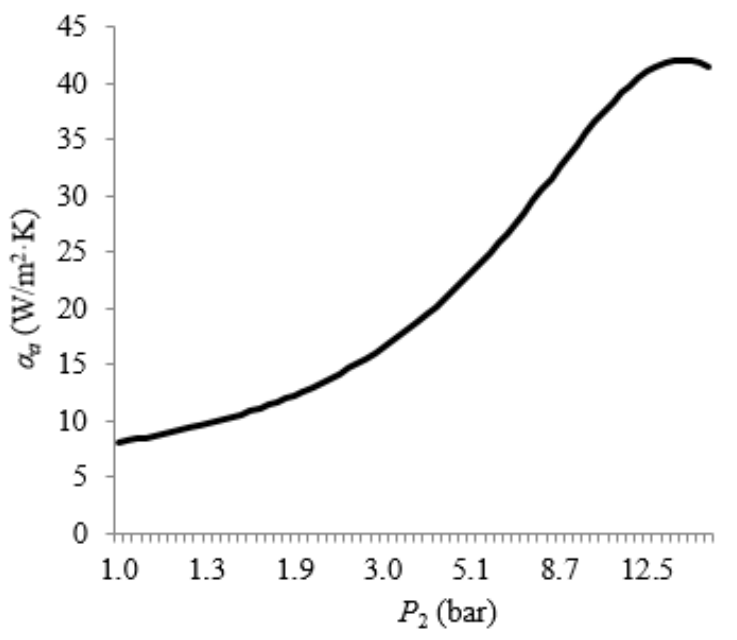




$$
P_{3}=\frac{P_{2} \cdot T_{3}}{T_{2}}
$$

249

250

251

252

253

254

where $P_{3}$ is the value of the working pressure at the end of the compression stroke, taking into account the balance of heat losses for heat transfer to the cylinder head elements, Pa.

The further consideration of the theoretical model should be supplemented with a criterion taking into account the wear degree of the CPG and the conditions accompanying the process of air leakage through the leaks of the CPG. The specified criterion $\beta$ will be determined as a ratio of the ambient pressure to the pressure in the combustion chamber, which can be written as follows:

$$
\beta=\frac{P_{0}}{P_{3}}
$$

where $P_{0}$ is the ambient pressure, $\mathrm{Pa} ; P_{3}$ is the pressure value at the end of the compression stroke, taking into account the heat transfer to the cylinder head, $\mathrm{Pa}$.

The value $\beta_{c r}$ for our calculation conditions is taken equal to 0.528 . When $\beta>\beta_{c r}$, there appears the mode of leakage from the cylinder called subcritical. The following operating condition applies for this mode:

$$
\omega=\sqrt{2 \frac{k}{k-1} R T_{3}\left[1-\left(\frac{P_{0}}{P_{3}}\right)^{\frac{k-1}{k}}\right]}
$$

Under the condition $\beta<\beta_{c r}$, there appears a critical variant of the air outflow through the CPG leaks described by the equation: 


$$
\omega_{c r}=\sqrt{2 \frac{k}{k-1} R T_{3}}
$$
269 discrete parts, we can determine the total air leakage through the leaks using the fol270 lowing equation:

$$
\Delta V=\frac{2}{6 n} \omega \cdot 10^{3} \cdot F
$$

272 where $F$ is the area of the equivalent cross-section of the CPG wear zone, $\mathrm{mm}^{2}$. pensating adiabatic expansion of the working volume of the compressed body. Taking 275 into account the compensating air expansion $\Delta V$, the pressure value at the end of the 276 compression stroke can be finally written by the following expression:

$$
P_{4}=P_{3}\left(\frac{V_{2}}{V_{2}+\Delta V}\right)^{k}
$$
280 the end of the compression stroke changes according to a nonlinear law, reaching its maximum at the point corresponding to 170 degrees. 


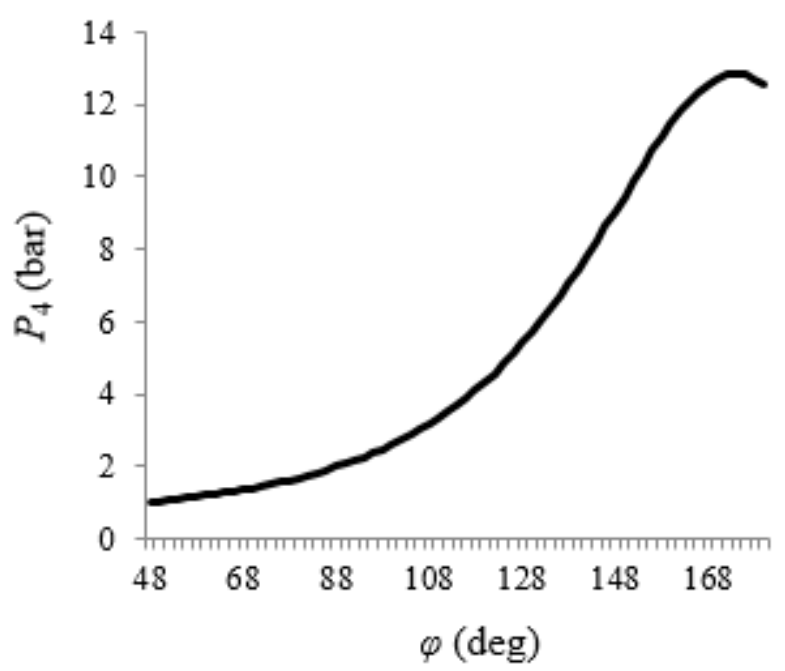

Figure 5. The dependence of the pressure value in the combustion chamber $P_{4}$ taking into account the air leakage from the cylinder and the heat air expansion, on the change in the ICE crankshaft rotation angle $\varphi$.

For the variant when the pressure value changes according to equation (15), the temperature will also change according to the nonlinear dependence, which gradient depends on the adiabatic coefficient:

$$
T_{4}=T_{3}\left(\frac{V_{2}}{V_{2}+\Delta V}\right)^{k}
$$

As a result of correlating private mathematical expressions, we considered the chronology of the change in the pressure and temperature value at the end of the compression stroke depending on the crankshaft rotation angle, taking into account the influence of several significant factors: changing leakage during the operation of vehicles, subcritical and critical variants of leakage through the CPG leaks, taking into account the heat transfer coefficient to the cylinder head and piston walls, heat expansion of the working fluid of the compressed air.

\section{Experimental research procedure}


The theoretical model provides for a constant crankshaft speed. In a real pro-

302 cess, the crankshaft speed changes significantly during one complete revolution. The 303 level of the battery charge, the power of mechanical losses, the technical condition of 304 the starter, the temperature of the oil and air affect considerably the variation in the 305 crankshaft speed $[31,32]$.

The cranking frequency of the engine crankshaft can be stabilized by monitoring the balance of the indicated power and the power of mechanical losses. In the experimental practice related to measuring angular revolution frequencies, it is known that several electronic means and methods for measuring angular rotation frequencies are used to improve accuracy; in our case, the accuracy of the applied angular frequency recorder was $2 \mathrm{rpm}$. Applying the comparison method based on the use of a high312 precision frequency meter together with our methodology, we will determine the error 313 of estimating the CPG wear degree depending on the method used to control the rotation frequency (speed) [33]. To this end, we determine the magnitude of the variation in the engine rpm speed in two speed control modes.

The variation in the ICE crankshaft speed and, accordingly, the variation in the change in the clearance are calculated using the measured oscillogram of the change in the crankshaft speed shown in Figure. 6. 


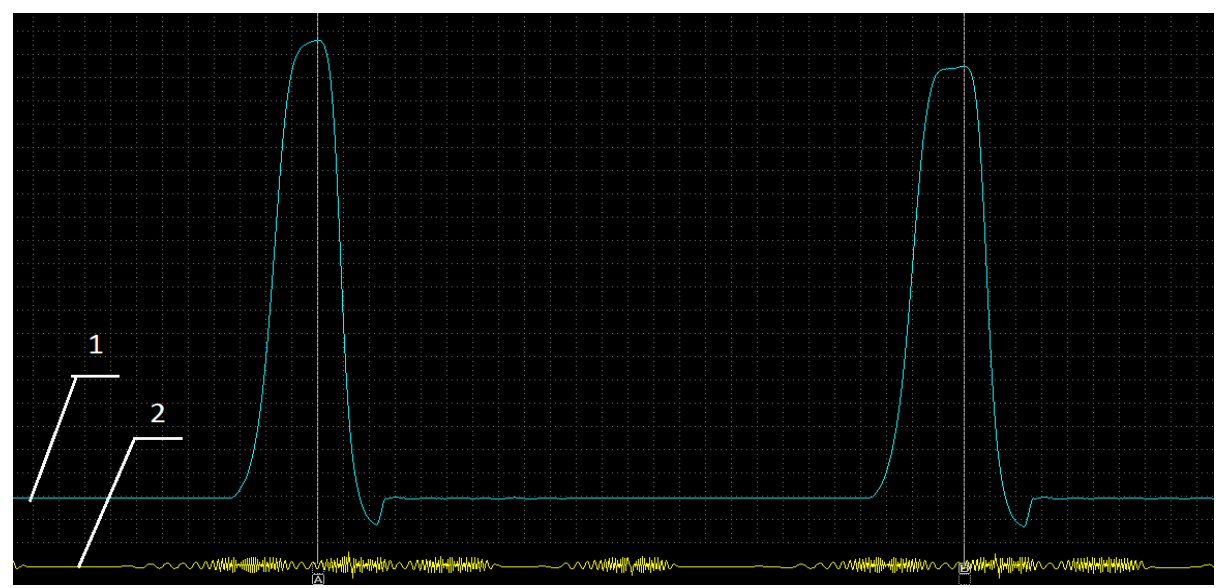

Figure 6. An oscillogram of the pressure in the above-piston space of the cylinder during leakage of $P=0.5 \mathrm{~mm}^{2}$ and changes in the engine crankshaft speed (the readings were recorded at the minimum allowable battery voltage (9V). Details: (1) oscillogram of the pressure in the above-piston space of the cylinder; (2) oscillogram of the crankshaft speed.

When processing the experimental data, the angular frequency was measured with an accuracy of $2 \mathrm{rpm}$ using the oscillogram recorded in the oscilloscope memory buffer. 2 teeth are omitted on the crankshaft gear for synchronization with the TDC position of the 1st cylinder. This omission and its graphic equivalent are recorded on the experimental oscillogram. The time is specified with millisecond precision. The average minimum cranking speed of the crankshaft at the battery voltage of $(9 \mathrm{~V})$ was $39-41 \mathrm{rpm}$ and the pressure value was $7.2-7.3$ bar, while the maximum speed was $85-$ $88 \mathrm{rpm}$ and the pressure value was $10.5-11$ bar.

3.1. The experimental research results and their technical and economic assessment

Any intermediate wear of the cylinder-piston group significantly affects the maximum pressure value at the end of the compression stroke and the phase, at which this maximum is realized. The displacement of the phase of applying the maximum pressure value is a sensitive diagnostic parameter of changing the leak integrity of the rings. 
The pressure at the end of compression and the phase of the appearance of this

pressure depend on several operating parameters:

1) Variation of the crankshaft speed when estimating the pressure value;

2) The degree of the battery contamination;

3) The power of mechanical losses and the throttle opening rate;

4) The operating temperature of the oil and cooling/anti-freezing liquid.

To determine the experimental applicability of the new method for diagnosing the $\mathrm{CPG}$, let us use the sensitivity coefficient of the adopted diagnostic parameter:

$$
K=\Delta \mathrm{P} / \Delta \mathrm{S}
$$

where $\Delta P$ is the change in the diagnostic parameter (change in the pressure value at the end of the compression stroke), bar, $\Delta S$ is the change in the structural parameter (total equivalent clearance in the $\mathrm{CPG}$ ), $\mathrm{mm}^{2}$.

When calculating the pressure sensitivity coefficient at the end of the compression stroke, we set the variation of the total equivalent cross-section in the range from $0.5 \mathrm{~mm}^{2}$ to $1.6 \mathrm{~mm}^{2}$. After sequential collecting of variants of the input experiment factors, we obtained the output data of the experiment used to plot the dependencies of the crankshaft speed with a step of $50 \mathrm{rpm}$ from 100 to $300 \mathrm{rpm}$ on the value of the equivalent cross-section of the CPG clearances.

The varying value of the equivalent resistance $\Delta S$ causes changes in the pressure value at the end of the compression stroke. After obtaining the experimental dependences, we calculated the values of the sensitivity coefficient $\Delta P$. 
365 for different modes of cranking the engine crankshaft by the starter. We plot the de366 pendence of the pressure at the end of the compression stroke on the wear of the piston 367 rings in various modes of cranking by the starter (Figure 7).

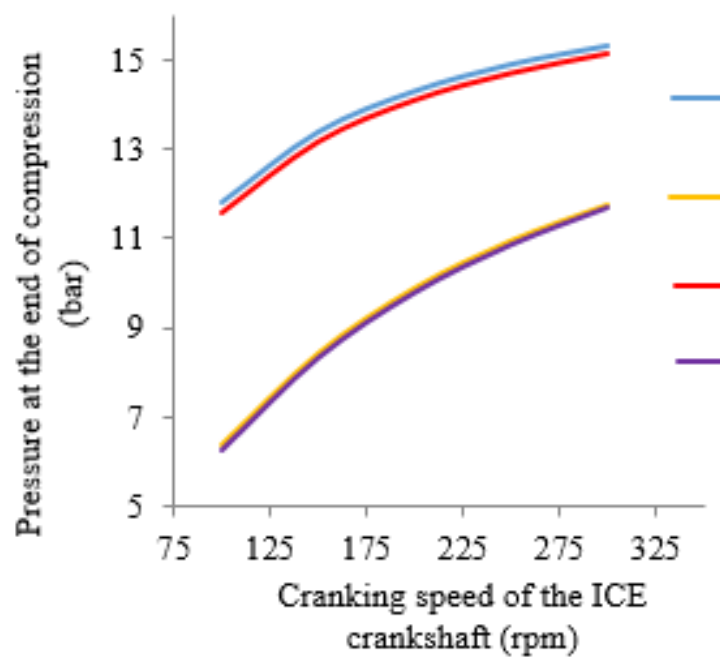

$P_{0.5}$ hot is the total equivalent cross-section of the ring wear of $0.5 \mathrm{~mm}^{2}$ when the ICE is heated to $90^{\circ} \mathrm{C}$ $P_{1.6}$ hot is the total equivalent cross-section of the ring wear of $1.6 \mathrm{~mm}^{2}$ when the ICE is heated to $90^{\circ} \mathrm{C}$ $P_{0.5}$ cold is the total equivalent cross-section of the ring wear of $0.5 \mathrm{~mm}^{2}$ with the cold ICE of $20^{\circ} \mathrm{C}$

$P_{1.6}$ cold is the total equivalent cross-section of the ring wear of $1.6 \mathrm{~mm}^{2}$ with the cold ICE of $20^{\circ} \mathrm{C}$

Figure 7. A change in the pressure at the end of the compression stroke depending on the wear of the piston rings in various modes of cranking with the starter.

An analysis of the graph in Figure 7 shows that an increase in the number of revolutions of the crankshaft when cranking with a starter leads to a polynomial change in the pressure value at the end of the compression stroke. The coolant temperature variation within the range from 20 to $90{ }^{\circ} \mathrm{C}$ does not affect the output parameter the pressure value at the end of the compression stroke.

Let us calculate the value of the sensitivity coefficient for the experimental dependence shown in Figure 7 and plot a dependence of the pressure sensitivity coefficient at the end of the compression stroke of worn piston rings at the variation of the crankshaft speed and engine temperature (Figure 8). 


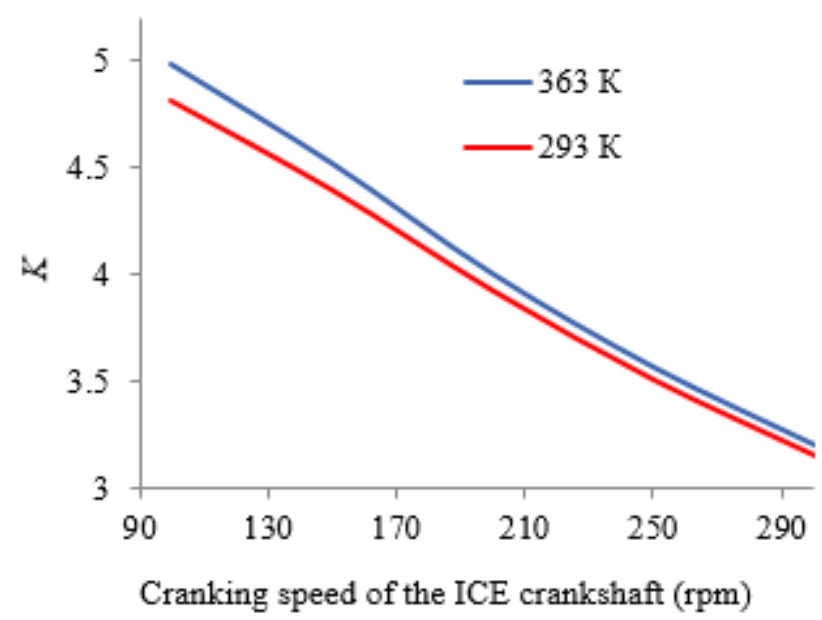

Figure 8. The dependence of the pressure sensitivity coefficient at the end of the comspeeds (100 rpm).

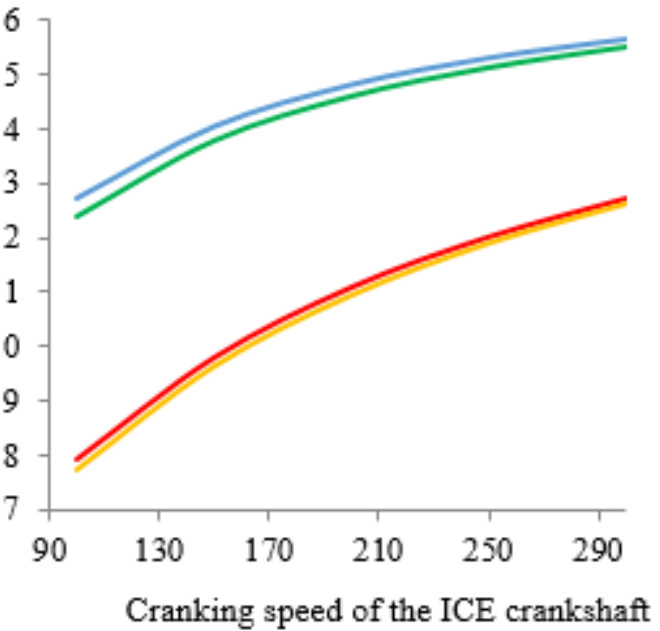

(rpm)

Figure 9. A change in the pressure at the end of the compression stroke depending on the cylinder wear in various modes of cranking by the starter. 
An analysis of the graph in Figure 9 shows that an increase in the number of

397 revolutions of the crankshaft when cranking with a starter leads to a quadratic change 398 in the pressure at the end of the compression stroke. The variation of the coolant tem399 perature within the range from 20 to $90^{\circ} \mathrm{C}$ neither affects the output parameter - the 400 pressure value at the end of the compression stroke.

Let us calculate the value of the sensitivity coefficient for the experimental de-

402

403

404

405

406

407

408

409

410

411

412

413

414

pendence shown in Figure 9 and plot a dependence of the pressure sensitivity coefficient at the end of the compression stroke of the worn cylinder liners at the variation of the crankshaft speed and engine temperature (Figure 10).

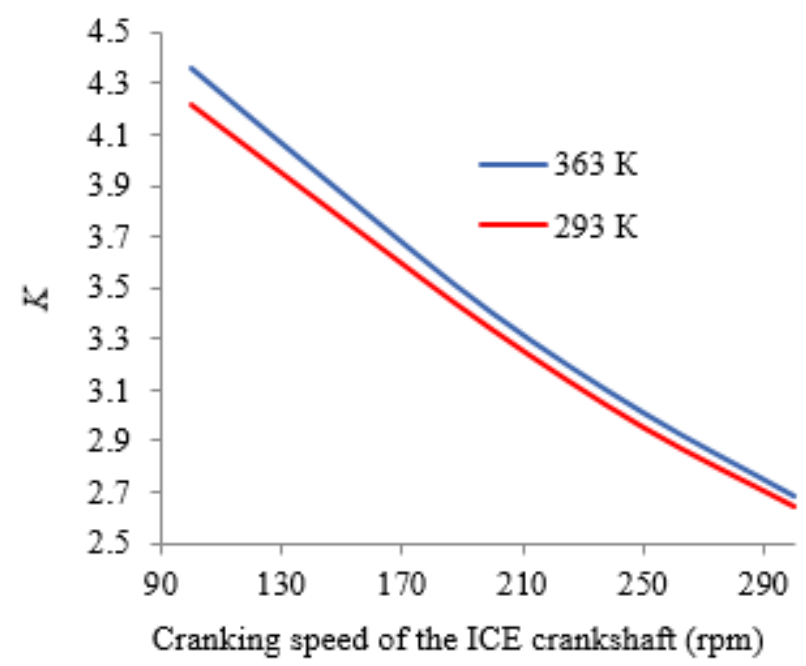

Figure 10. The dependence of the pressure sensitivity coefficient at the end of the compression stroke of the worn cylinder liners at the variation of the crankshaft speed and engine temperature.

An analysis of the graph in Figure 10 shows that the pressure sensitivity at the end of the compression stroke also takes on the maximum values at low engine speeds (100 rpm).

To calculate the displacement of the maximum pressure phase depending on various diagnostic modes, we carried out experimental studies, which resulted in a de- 
415 pendence of the maximum pressure phase in the tested cylinders relative to the TDC 416 when the piston rings are worn (Figure 11).

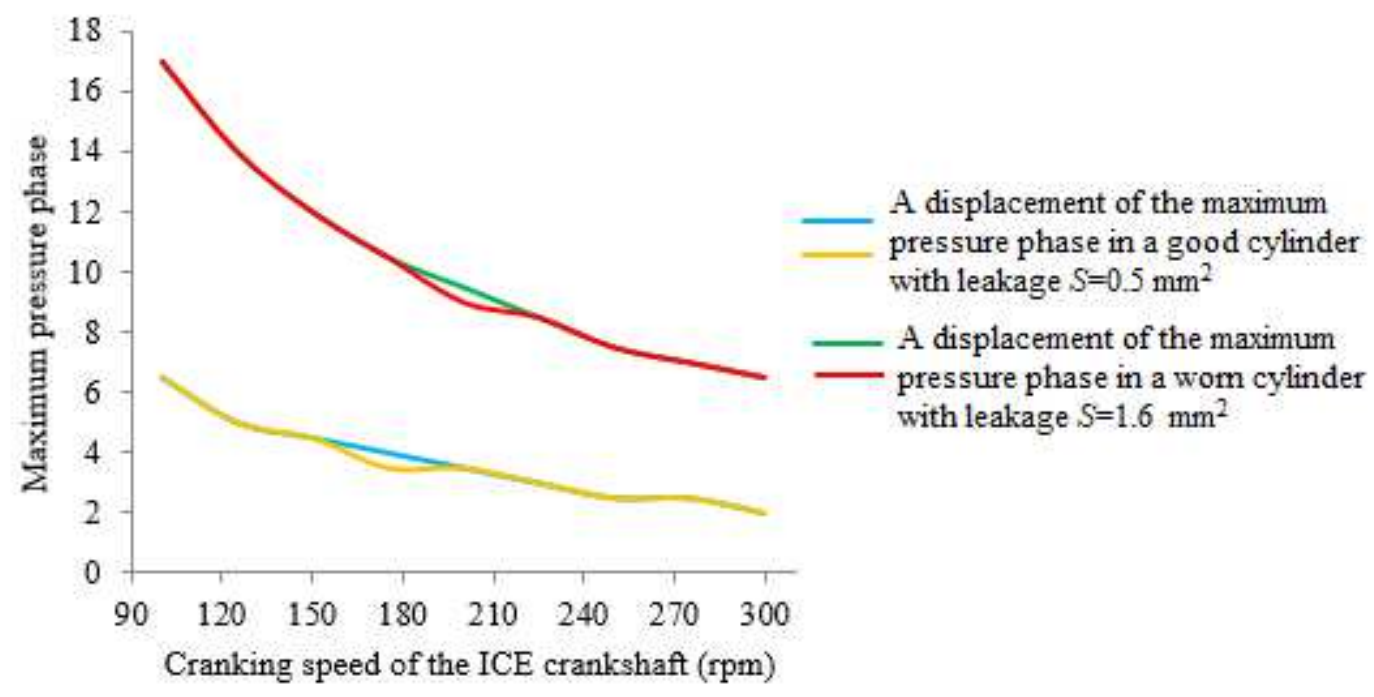

417

418

419

420

421

422

$423(100 \mathrm{rpm})$.

424

425 pendence shown in Figure 11 and plot a dependence of the sensitivity coefficient of 426 the phase displacement when the piston rings are worn, at the variation in the crank-

427 shaft speed (Figure 12). 


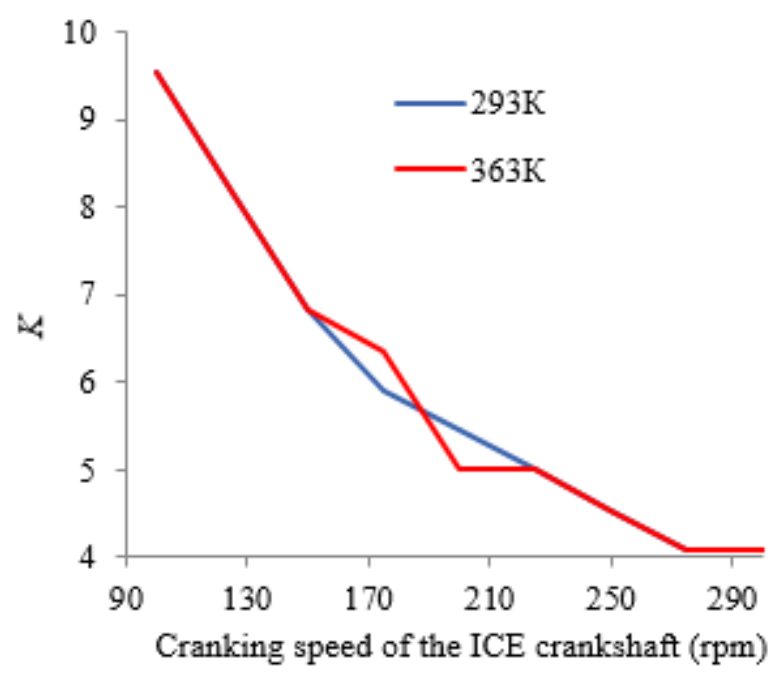

Figure 12. The dependence of the sensitivity coefficient of the phase displacement when the piston rings are worn, at the variation in the crankshaft speed.

An analysis of the graph in Figure 12 shows that the phase sensitivity coefficient when the piston rings are worn takes on the maximum values at low engine crankshaft speeds $(100 \mathrm{rpm})$.

\section{Conclusions}

The complex of the theoretical and experimental research revealing the relationship between the pressure at the end of the compression stroke and the technical condition of the cylinder-piston group, the methodological approaches to the implementation of the developed method, and the operational research and processing of the obtained material allowed us to establish the following:

The results of the theoretical research dealing with the justification of the ICE CPG testing technology, which consider the main elements of the system and a stepby-step study of the process of air filling and compression, allowed us to establish the mathematical dependences of the air pressure formation process in the combustion chamber, the equations describing the movement of air through the elements of the 
CPG, GDM, cylinder head, and the alleged mechanism of their influence on the pressure and phase parameters in the course of the dynamic control based on the new oscillographic method. The practical value of the work lies in determining new methods and modes for diagnosing the ICE CPG based on the implementation of test impacts. The use of the proposed ICE CPG testing technologies will allow us to significantly reduce the maintenance and repair costs, considerably reduce the number of CPG failures, avoid power losses and excessive fuel consumption, and increase the reliability of modern vehicles.

We obtained a diagnostic model allowing us to determine the pressure at the end of compression during the cylinder wear, taking into account the main factors affecting this parameter (the thickness of the heat transfer wall, the material of the block and the cylinder head, the power of mechanical losses is unchanged). We established that the main error of the diagnostic model is caused by the fact that the actual leakage is not taken into account depending on the position of the piston. The diagnostic model takes into account the engine temperature range from $20^{\circ} \mathrm{C}$ to $90^{\circ} \mathrm{C}$ and the air temperature range from 20 воздухаС to $30^{\circ} \mathrm{C}$.

We established that the most sensitive diagnostic parameter of the liner ring wear is the maximum pressure at the end of compression when the crankshaft is in the upper part of the cylinder (TDC). A sensitive diagnostic parameter of the ring wear is the pressure phase value relative to the crankshaft rotation angle. The maximum sensi468 tivity of the pressure and phase parameter is set during cranking at the minimum 469 crankshaft speed equal of $100 \mathrm{rpm}$. 
The technical and economic assessment of the diagnostic algorithms and the

471 complex technology showed that it is highly efficient to apply the developed method:

472 the labor intensity of the preparatory and final operations decreased by $80 \%$, the error

473 of the measuring channel was 0.87 , the diagnostic reliability increased to $0.95-0.97$.

\section{Declarations}

\section{Availability of data and materials}

Not applicable.

\section{Competing interests}

The authors declare that they have no competing interests.

\section{Funding}

Not applicable.

\section{Authors' contributions}

VS and SB designed research, performed research, analyzed the data, and wrote the paper. AG was a major contributor in writing the manuscript. All authors suggested related works, discussed the structure of the paper and results. All authors read and approved the final manuscript.

\section{Acknowledgements}

Not applicable.

\section{References}

1. A N Mitrofanov, G M Tret'yakov, S V Kopeikin. Predicting the energysupply parameters for a transportation process based on multifactor models, Russian Electrical Engineering, 2017, 88: 109-114. https://doi.org/10.3103/S1068371217030130.

2. V Aulin, A Hrinkiv, A Dykha, M Chernovol, O Lyashuk, S Lysenko. Substantiation of diagnostic parameters for determining the technical condition of transmission assemblies in trucks. Eastern-European Journal of Enterprise Technologies, 2018, 2 (1(92)): 4-13. https://doi.org/10.15587/1729-4061.2018.125349. 
3. E V Ageev, A Y Altukhov, A V Scherbakov, A N Novikov. Informative-

ness increasing of internal combustion engines diagnosis due to technical endoscope. Journal of Engineering and Applied Sciences, 2017, 12 (4): 1028-1030. http://doi.org/10.3923/jeasci.2017.1028.1030.

4. G Zheng, X Yu, J Liu, T Song, W Li. Performance development target setting of passenger car diesel engine. Chinese Journal of Mechanical Engineering (English Edition), 2013, 26 (3): 512-517. http://doi.org/10.3901/CJME.2013.03.512.

5. Mollenhauer K, Tschoke H. Handbook of diesel engines. Heidelberg: Springer, 2010.

6. Dempsey P. Troubleshooting and repairing diesel engines. New York: McGraw-Hill, 2008.

7. A Plaksin, A Gritsenko, K Glemba. Experimental studies of cylinder group state during motoring. 2nd International Conference on Industrial Engineering, Procedia Engineering, Chelyabinsk, Russian Federation, 19 - 20 May 2016, 2016, 150: 1188-1191. https://doi.org/10.1016/j.proeng.2016.07.234.

8. A Gritsenko, S Kukov, K Glemba. Theoretical underpinning of diagnosing the cylinder group during motoring. 2nd International Conference on Industrial Engineering, Procedia Engineering, Chelyabinsk, Russian Federation, 19 - 20 May 2016, 2016: 1182-1187. https://doi.org/10.1016/j.proeng.2016.07.233.

9. A Gasparjans, A Terebkovs, A Ziravecka. Application of mathematical methods for current diagnostics of cylinder-piston group elements of diesel engines, 19th International Scientific Conference Engineering for Rural Development. Engineering for Rural Development, 2020, 19: 331-340. https://doi.org/10.22616/ERDev2020.19.TF078

10. I Davydov, I Konkova, A Konkov. Diagnostic criteria for the signal of the first-order derivative of diesel engine in-cylinder pressure. 8th International Scientific Siberian Transport Forum, Advances in Intelligent Systems and Computing, Novosibirsk, Russian Federation, 22-27 May 2019, 2019, 1115: 329-339. https://doi.org/10.1007/978-3-030-37916-2_32 . 
11. S Ovcharenko, V Minakov. Model of formation of wear debris concentration in diesel engine oil during operation. 8th International Scientific Siberian Transport Forum, Advances in Intelligent Systems and Computing, Novosibirsk, Russian Federation, 22-27 May 2019, 2019, 1115: 484-492. https://doi.org/10.1007/978-3030-37916-2_47.

12. S Ovcharenko, V Minakov. Application of the artificial neural networks for diesel diagnostics. 28th DAAAM International Symposium on Intelligent Manufacturing and Automation, Annals of DAAAM and Proceedings of the International DAAAM Symposium, Zadar, Croatia, 8-11 November 2017, 2017: 1208-1212. https://doi.org/10.2507/28th.daaam.proceedings.168.

13. Yu Skripnik, V Gorkun, K Shevchenko. Radiowave method of internal combustion engines' condition estimation. 16th International Crimean Microwave and Telecommunication Technology, Sevastopol, Ukraine, 11-15 September 2006, 2006, 4023516: 861-863. https://doi.org/10.1109/CRMICO.2006.256234

14. M A H Mollah. Evaluation of combustion chamber leakage for the maintenance of four stroke marine diesel engines. ASME Design Engineering Technical Conferences and Computers and Information in Engineering Conference, American Society of Mechanical Engineers, Design Engineering Division (Publication) DE, Pittsburg, б United Statesб 2001: 59-71.

15. A Gasparjans, A Terebkovs, A Ziravecka. Theoretical and experimental analysis of technical condition of piston rings of vessel diesel installations by method of resonance oscillations. 18th International Scientific Conference Engineering for Rural Development, Jelgava, Latvia, 22-24 May 2019, 2019, 18: 1287-1294. https://doi.org/10.22616/ERDev2019.18.N181.

16. R H R Gutiérrez, C R P Belchior, L A Vaz, U A Monteiro. Diagnostic methodology in four-stroke marine diesel engine by identifying operational parameters. Journal of the Brazilian Society of Mechanical Sciences and Engineering, 2018, 40 (10 (500)). https://doi.org/10.1007/s40430-018-1416-X.

17. D T Hountalas, G C Mavropoulos, G Kourbetis. Experimental investigation to develop a methodology for estimating the compression condition of Diesel en- 
558 gines. Energy Conversion and Management, 2006, 47 (1): 1-18.

559 https://doi.org/10.1016/j.enconman.2005.04.001.

560 18. F J Cavalieri, F Zenklusen, A Cardona. Determination of wear in internal 561 combustion engine valves using the finite element method and experimental tests.

562

563

564

565

566

567

568

569

570

571

572

573

574

575

576

577

578

579

580

581

582

583

584

585

586

Mechanism and Machine

Theory,

2016 ,

104:

81-99. https://doi.org/10.1016/j.mechmachtheory.2016.05.017.

19. J Zhang, C W Liu, F R Bi, X B Bi, X Yang. Fault feature extraction of diesel engine based on bispectrum image fractal dimension. Chinese Journal of Mechanical Engineering (English Edition), 2018, 31 (2 (40)). https://doi.org/10.1186/s10033018-0230-9.

20. E V Ageev, A L Kudryavtsev, A L Sevastiyanov. The algorithm for diagnosing a cylinder-piston group using the technical endoscope. World of Transport and Technological Machinery, 2012, 1: 116-122 (in Russian).

21. Y Liu, M Qiao, S Jia, Anomaly detection for health assessment and prediction of diesel generator set. 4th International Conference on Communication and Information Processing, Ocean University of ChinaQingdao, China, 2-4 November 2018, 2018: 212-216. https://doi.org/10.1145/3290420.3290464

22. R Lewis, R Dwyer-Joyce, T Slatter, A Brooks. Valve recession: From experiment to predictive model. VDI Berichte, 2004, 1813: 79-93.

23. R Lewis, R S Dwyer-Joyce, G Josey. Design and development of a bench test-rig for investigating diesel engine inlet valve and seat wear. Transactions of Mechanical Engineering, 2000, 24: 39-46.

24. R Lewis, R Dwyer-Joyce, G Josey. Investigation of wear mechanisms occurring in passenger car diesel engine inlet valves and seat insert. SAE Technical Paper Series 1999-01-1216.

25. A Gritsenko, V Shepelev, E Zadorozhnaya, Z Almetova, A Burzev. The advancement of the methods of vibro-acoustic control of the ICE gas distribution mechanism. FME Transactions, 2020, 48 (1): 127-136. https://doi.org/10.5937/fmet2001127G. 
26. M Grujicic, J S Snipes, N Chandrasekharan. Fluid-structure interaction

588

589

590

591

592

593

594

595

596

597

598

599

600

601

602

603

604

605

606

607

608

609

610

611

612

613

614

computational analysis of a piston-cylinder based blast-wave-mitigation concept. Multidiscipline Modeling in Materials and Structures, 2012, 8 (4): 524-553. https://doi.org/10.1108/15736101211281632.

27. G F Molinar, P C Cresto, L Bianchi, R Maghenzani. Elastic distortions in simple piston-cylinder units at pressures up to $100 \mathrm{MPa}$. High Pressure Research, 1990, 5 (1-6): 801-803. https://doi.org/10.1080/08957959008246263.

28. A Doikin, K Gavrilov. Experimental modeling of wearing the friction surfaces of "piston-cylinder" tribounit. 5th International Conference on Industrial Engineering, Lecture Notes in Mechanical Engineering, 25-29 March 2019, Sochi, Russian Federation, 2020: 1225-1231. https://doi.org/10.1007/978-3-030-22041-9_127

29. I Klianar, A Stefanovic, M Rajkovic. Possibilities of piston-cylinder diagnostics of fits of motors. Tribology in Industry, 1999, 21 (1): 12-16.

30. A G Catto, A T Prata. A numerical study of instantaneous heat transfer during compression and expansion in piston-cylinder geometry. Numerical Heat Transfer, Part A: Applications, 2000, $38 \quad$ (3): 281-303. https://doi.org/10.1080/10407780050136530.

31. G H Nacke, V Nietzold. Diagnosis of the piston/cylinder assembly in internal combustion engines by means of the density function. MESS. STEUERN REGELN, 2017, 23 (4 Apr. 1980): 194-199.

32. A E Popov, Z V Almetova, V D Shepelev. Calculated analysis of efficiency of fresh charge heating in diesel engine under cold-start conditions. 5th International Conference on Industrial Engineering, Lecture Notes in Mechanical Engineering, 25-29 March 2019, Sochi, Russian Federation, 2020:559-566. https://doi.org/10.1007/978-3-030-22041-9_60.

33. A Gritsenko, V Shepelev, E Zadorozhnaya, K Shubenkova. Test diagnostics of engine systems in passenger cars. FME Transactions, 2020, 48 (1): 46-52. https://doi.org/10.5937/fmet2001046G. 
Figures

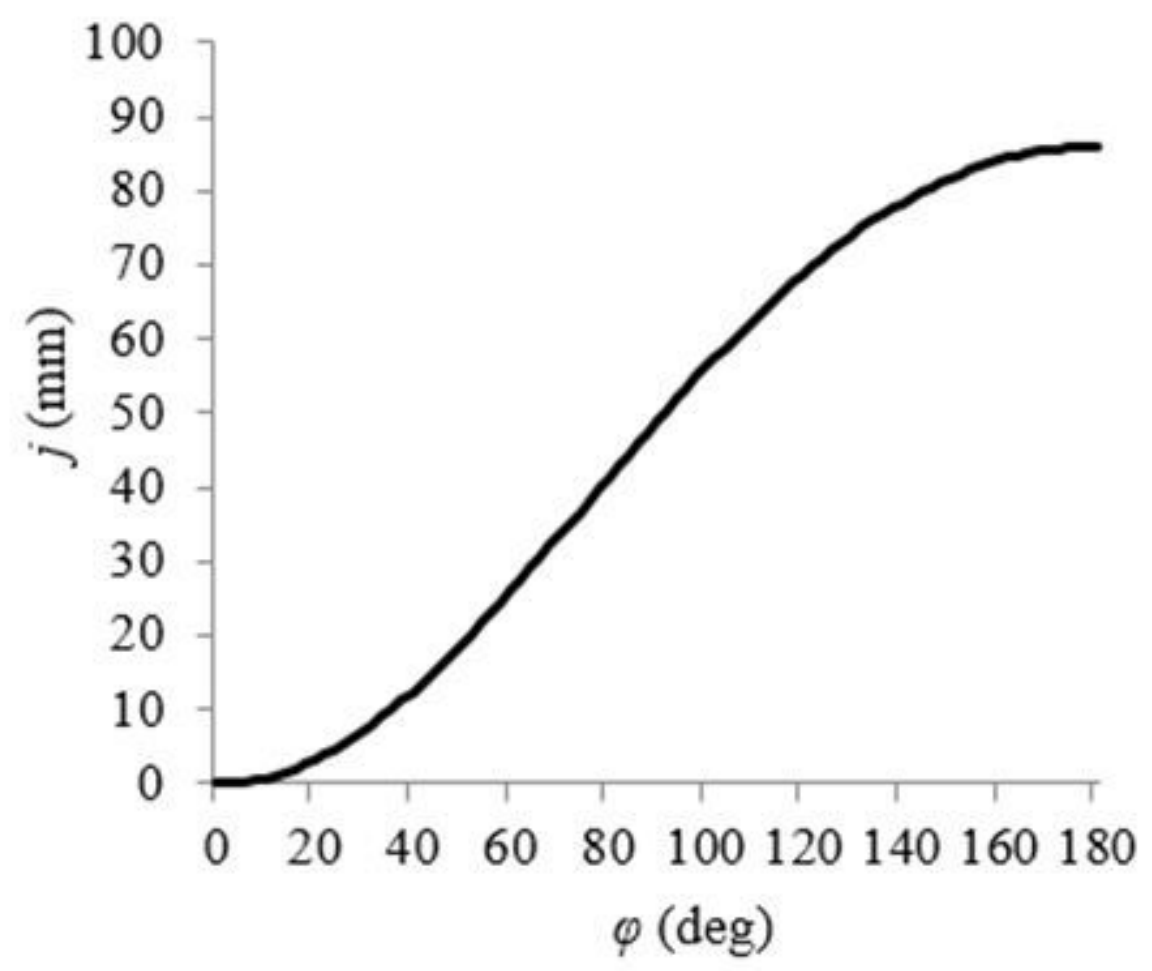

\section{Figure 1}

The calculated dependence of the working stroke of the piston value $j$ on the change in the engine crankshaft rotation angle $\varphi$. 


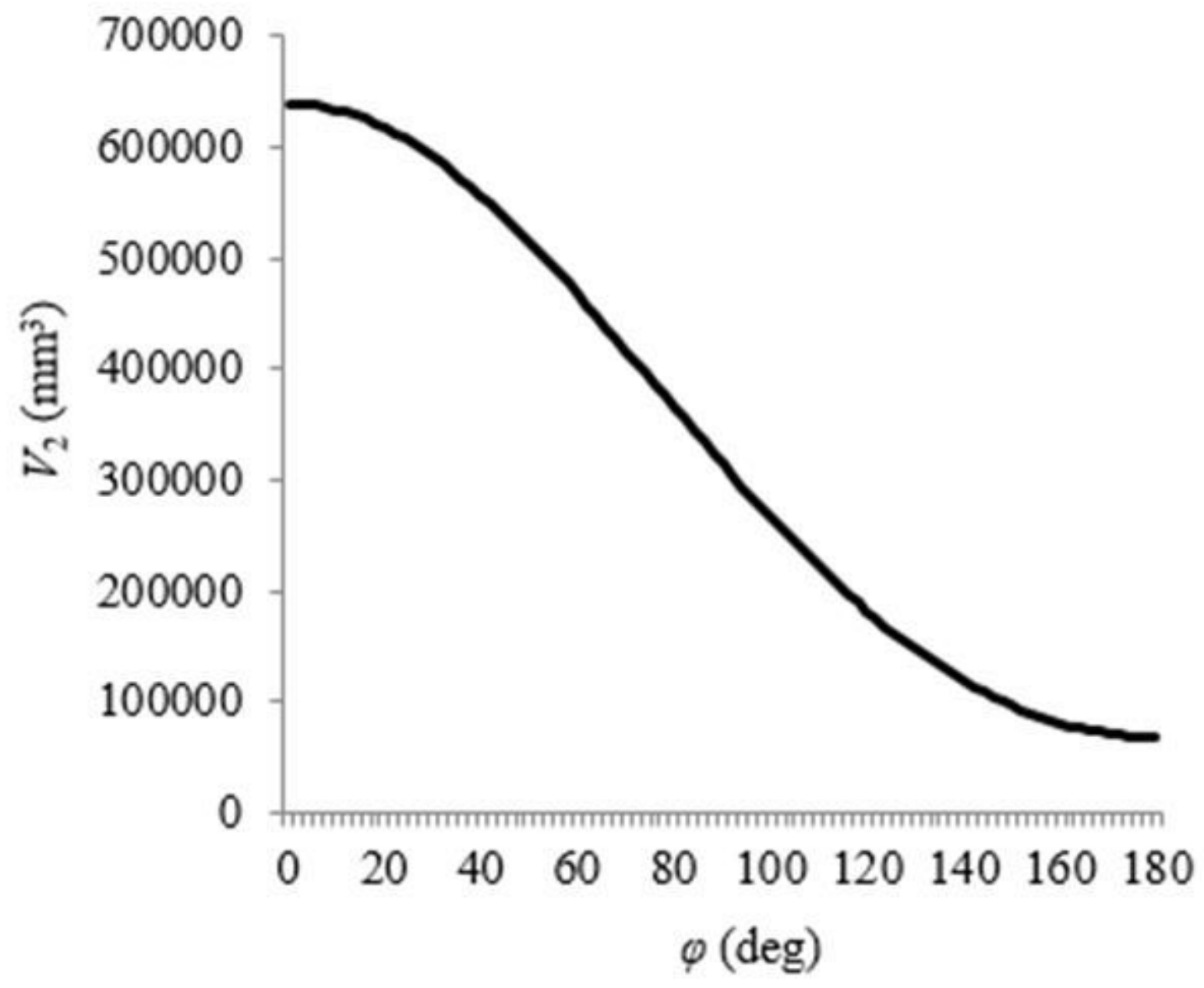

Figure 2

The operating characteristic of the change in volume in the space above the piston V2 depending on the change in the ICE crankshaft rotation angle $\varphi$. 


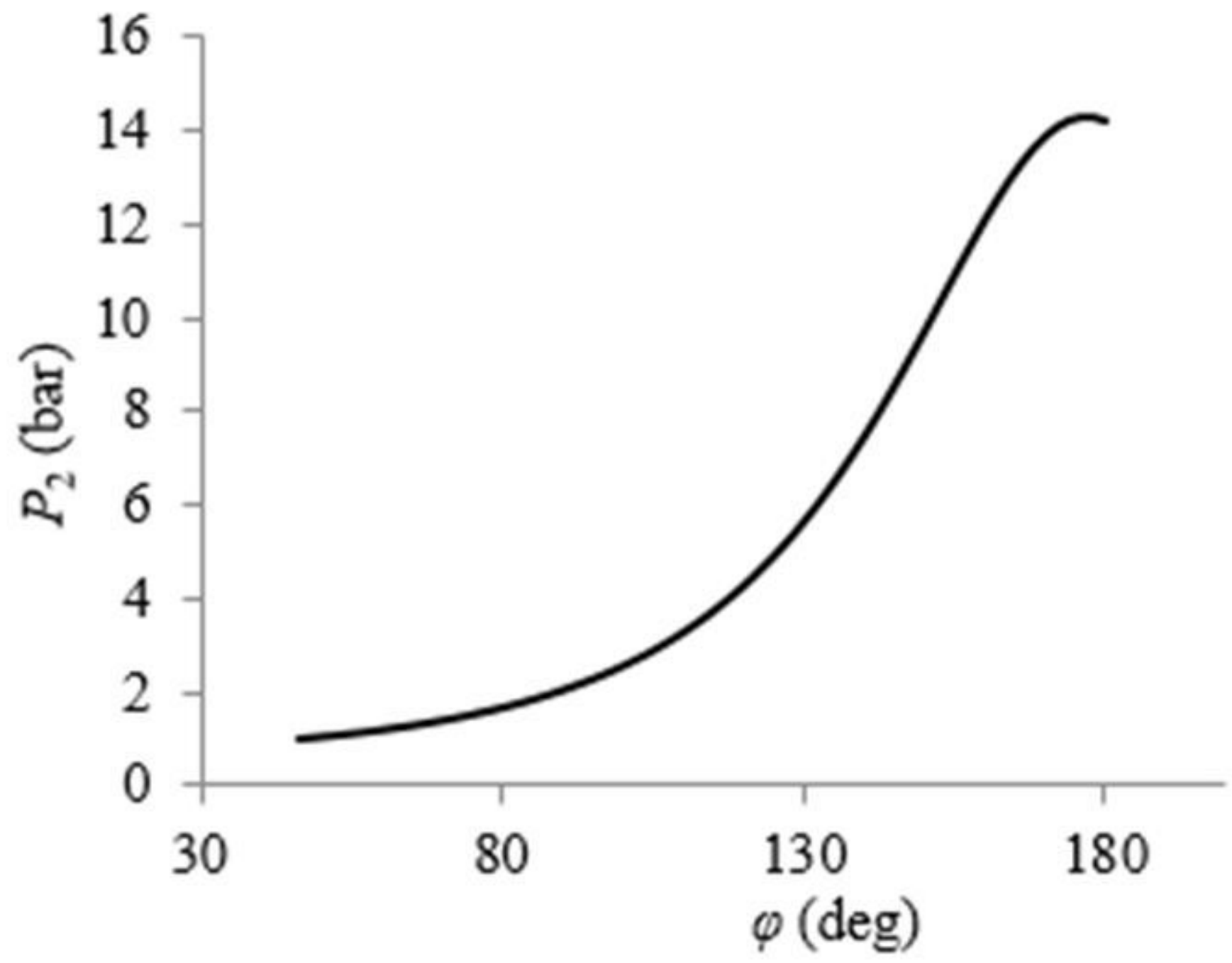

Figure 3

The dependence of the change in the pressure value in the combustion chamber P2 on the change in the ICE crankshaft rotation angle $\varphi$. 


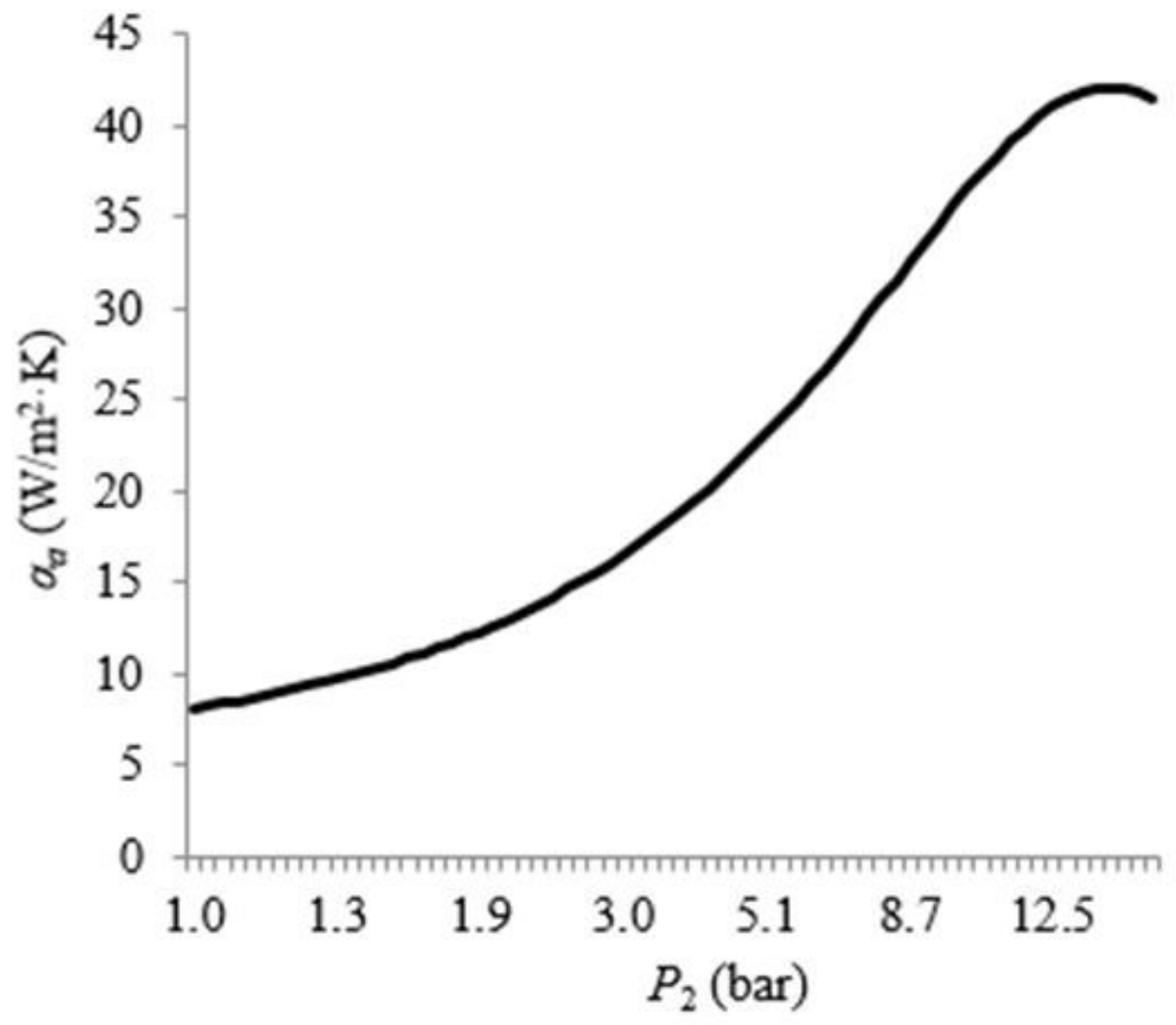

Figure 4

The dependence of the air heat transfer coefficient aa on the air pressure in the combustion chamber P2. 


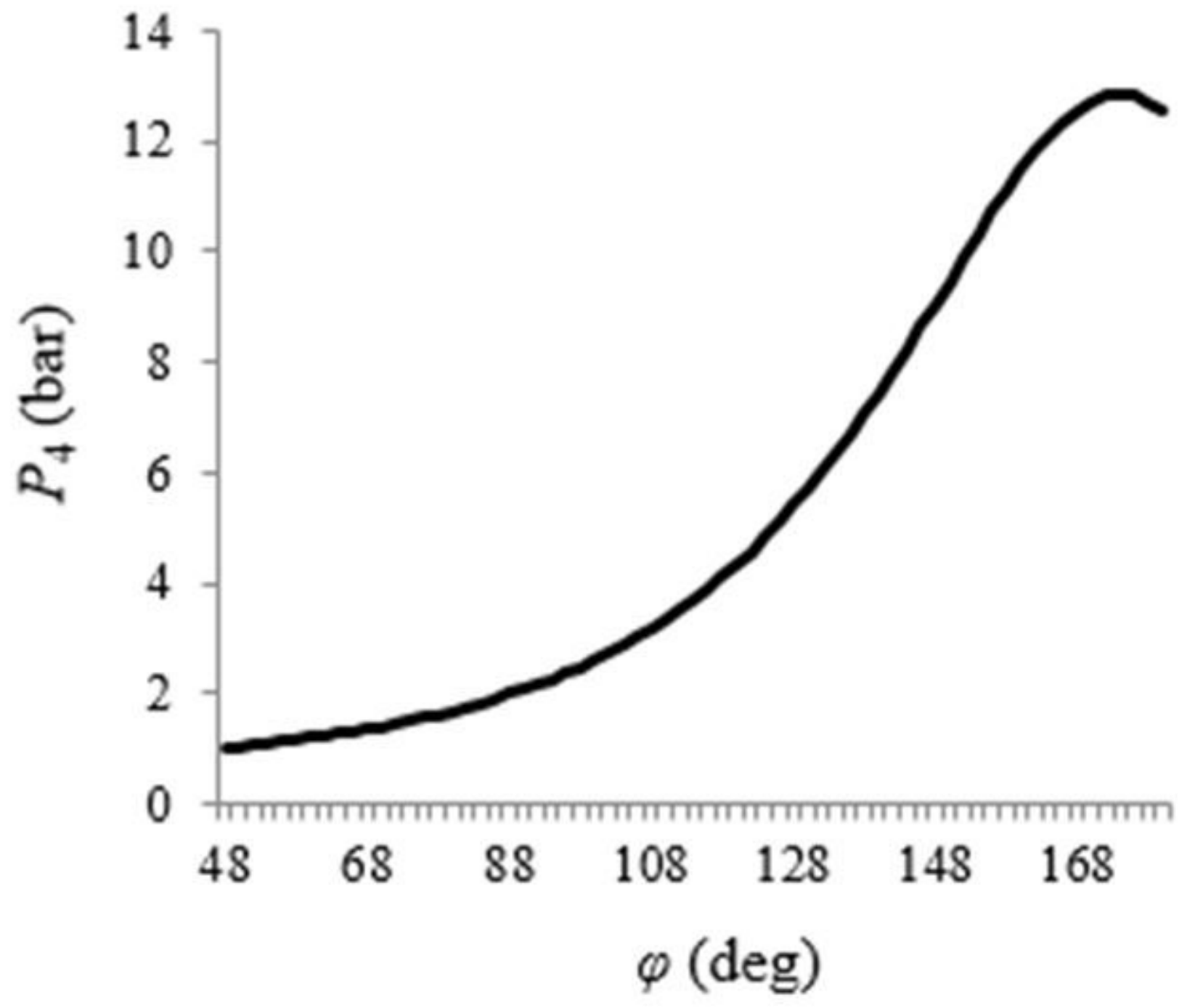

Figure 5

The dependence of the pressure value in the combustion chamber P4 taking into account the air leakage from the cylinder and the heat air expansion, on the change in the ICE crankshaft rotation angle $\varphi$. 


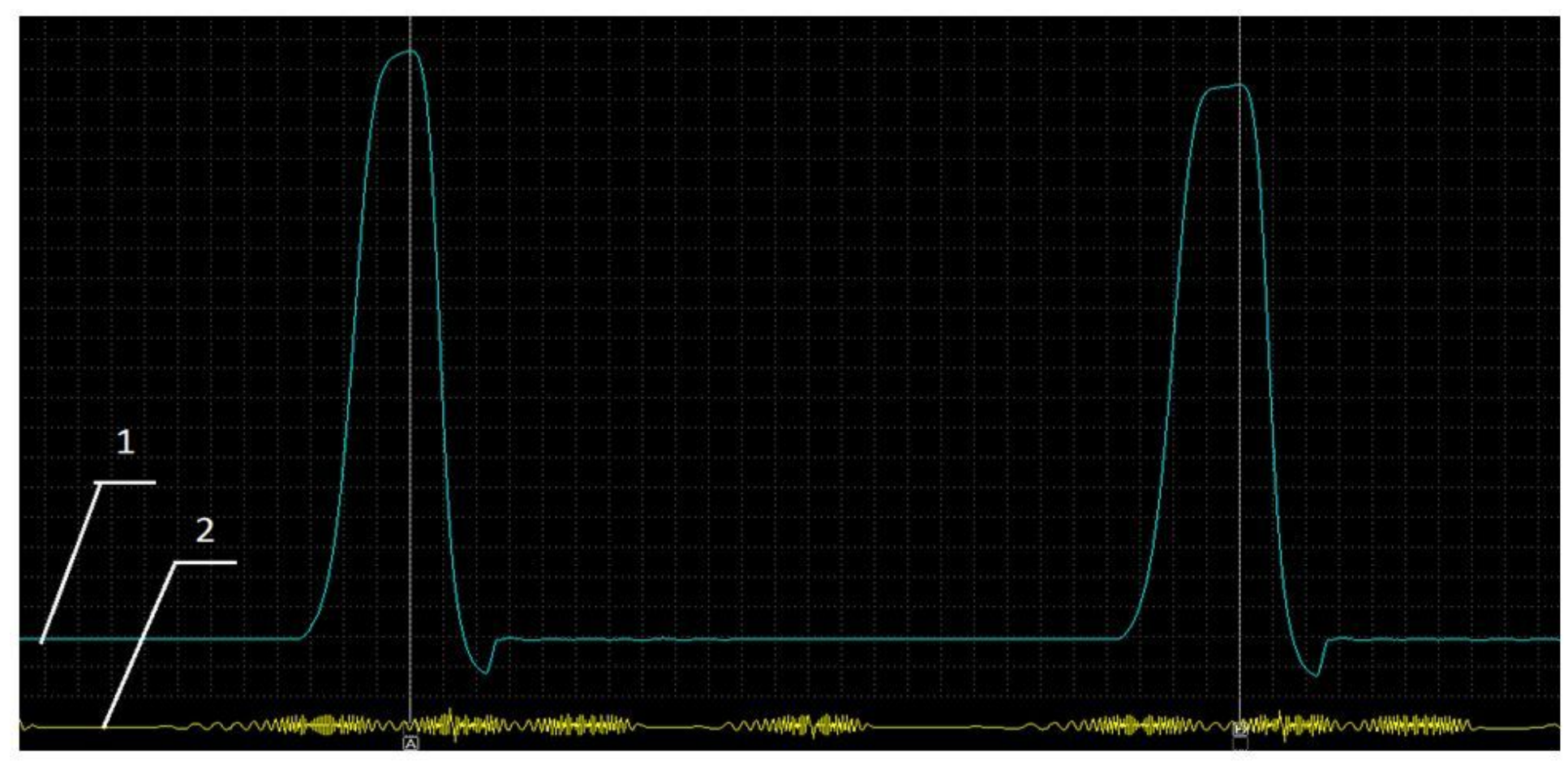

Figure 6

An oscillogram of the pressure in the above-piston space of the cylinder during leakage of $P=0.5 \mathrm{~mm} 2$ and changes in the engine crankshaft speed (the readings were recorded at the minimum allowable battery voltage (9V). Details: (1) oscillogram of the pressure in the above-piston space of the cylinder; (2) oscillogram of the crankshaft speed.

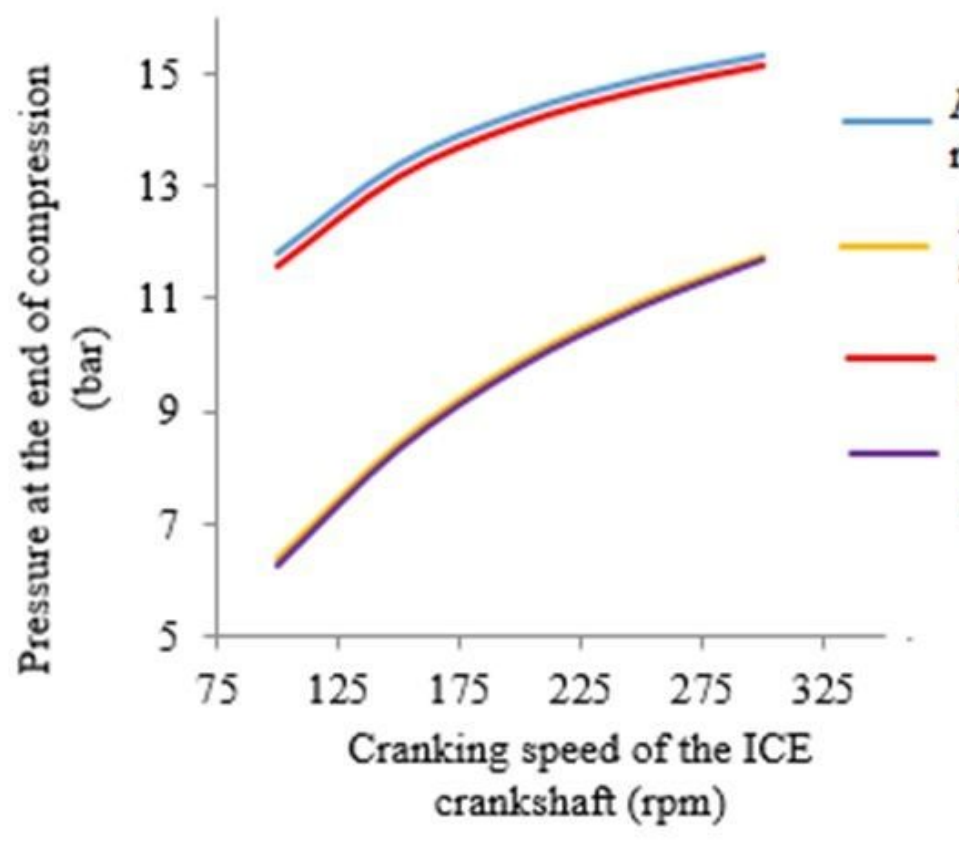

$P 0.5$ hot is the total equivalent cross-section of the ring wear of $0.5 \mathrm{~mm}^{2}$ when the ICE is heated to $90^{\circ} \mathrm{C}$ $P_{1.6}$ hot is the total equivalent cross-section of the ring wear of $1.6 \mathrm{~mm}^{2}$ when the ICE is heated to $90^{\circ} \mathrm{C}$ $P 0.5$ cold is the total equivalent cross-section of the ring wear of $0.5 \mathrm{~mm}^{2}$ with the cold ICE of $20^{\circ} \mathrm{C}$ $P_{1.6}$ cold is the total equivalent cross-section of the ring wear of $1.6 \mathrm{~mm}^{2}$ with the cold ICE of $20^{\circ} \mathrm{C}$

Figure 7 
A change in the pressure at the end of the compression stroke depending on the wear of the piston rings in various modes of cranking with the starter.

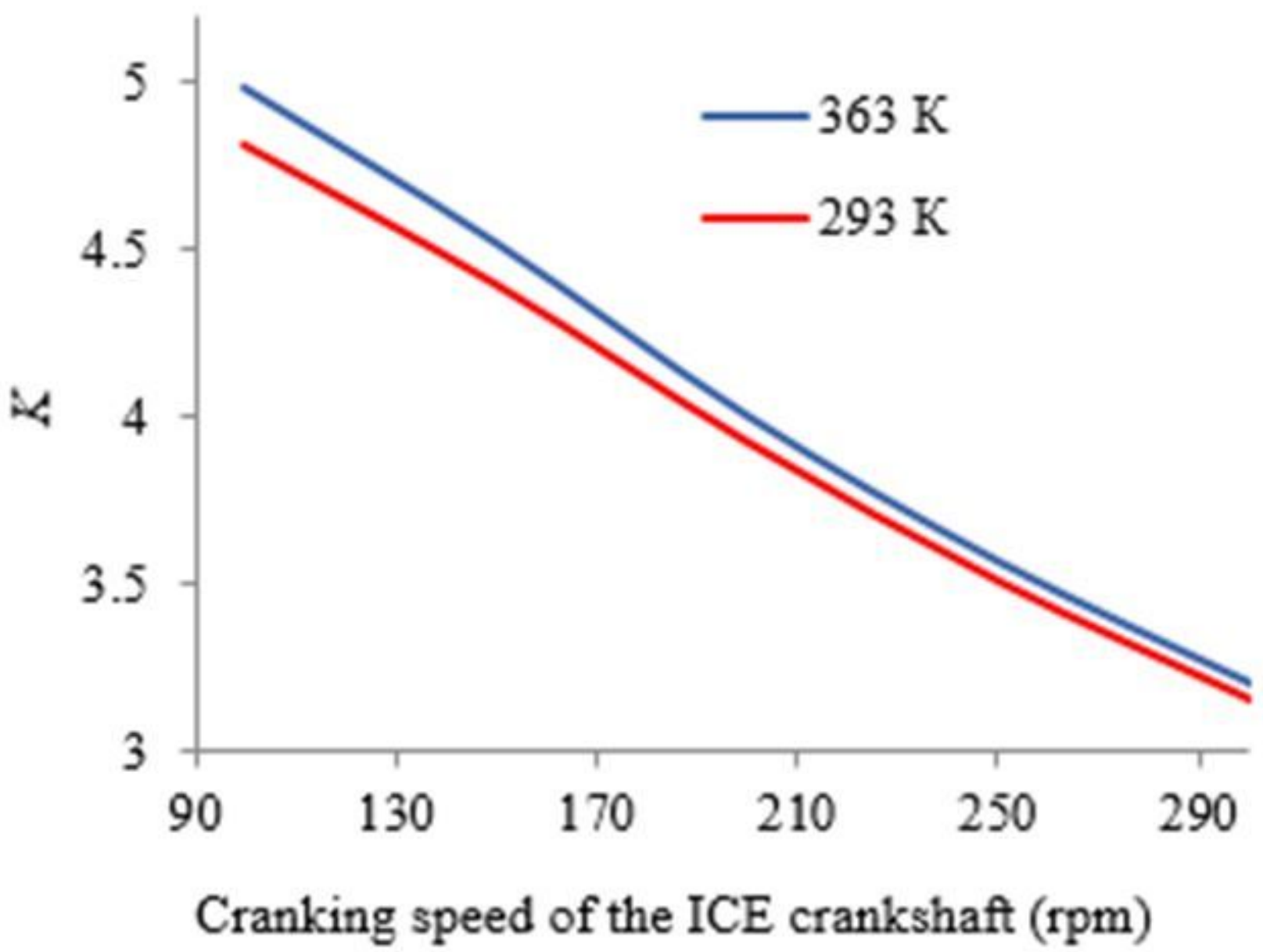

Figure 8

The dependence of the pressure sensitivity coefficient at the end of the com-pression stroke of the worn piston rings at the variation of the crankshaft speed and engine temperature 


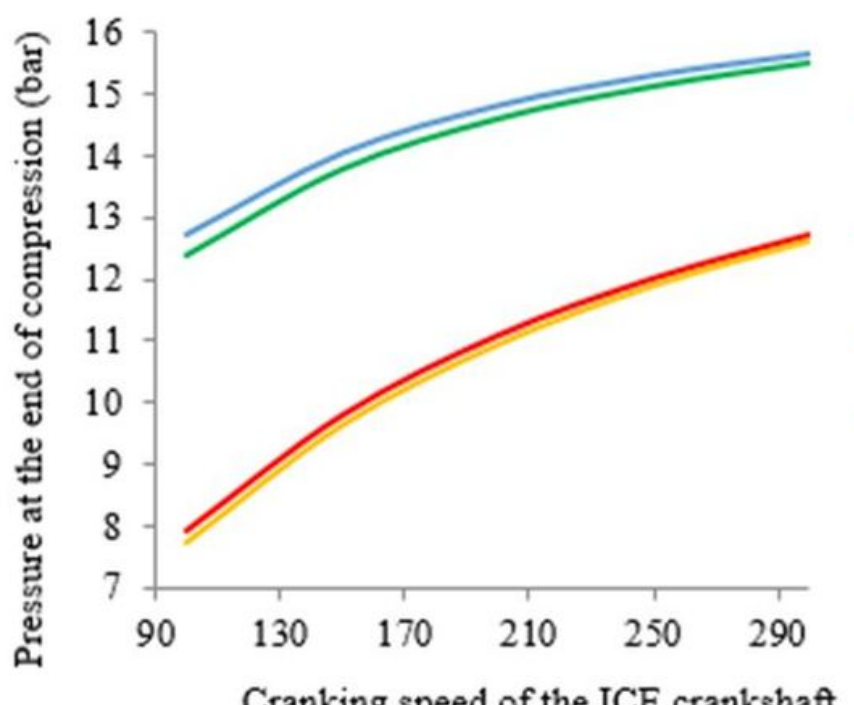

$P_{0.5 \text { hot }}$ is the total equivalent cross-section of the cylinder wear of $0.5 \mathrm{~mm}^{2}$ when the ICE is heated to $90^{\circ} \mathrm{C}$ $P_{1.6}$ hot is the total equivalent cross-section of the cylinder wear of $1.6 \mathrm{~mm}^{2}$ when the ICE is heated to $90^{\circ} \mathrm{C}$ $P 0.5$ cold is the total equivalent cross-section of the cylinder wear of $0.5 \mathrm{~mm}^{2}$ with the cold ICE of $20^{\circ} \mathrm{C}$ $P_{1.6 c o l d}$ is the total equivalent cross-section of the cylinder wear of $1.6 \mathrm{~mm}^{2}$ with the cold ICE of $20^{\circ} \mathrm{C}$

(rpm)

\section{Figure 9}

A change in the pressure at the end of the compression stroke depending on the cylinder wear in various modes of cranking by the starter.

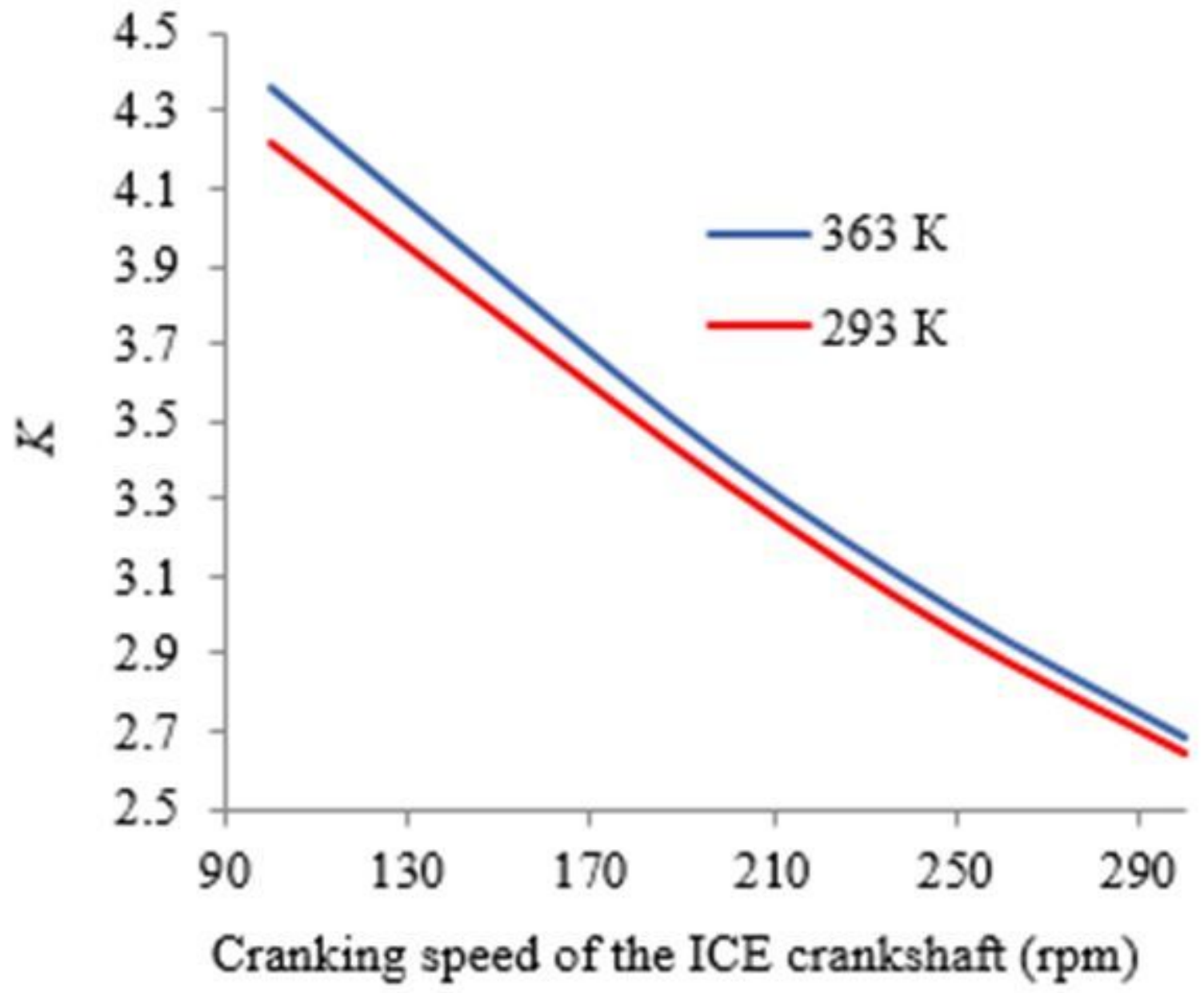


The dependence of the pressure sensitivity coefficient at the end of the compression stroke of the worn cylinder liners at the variation of the crankshaft speed and engine temperature.

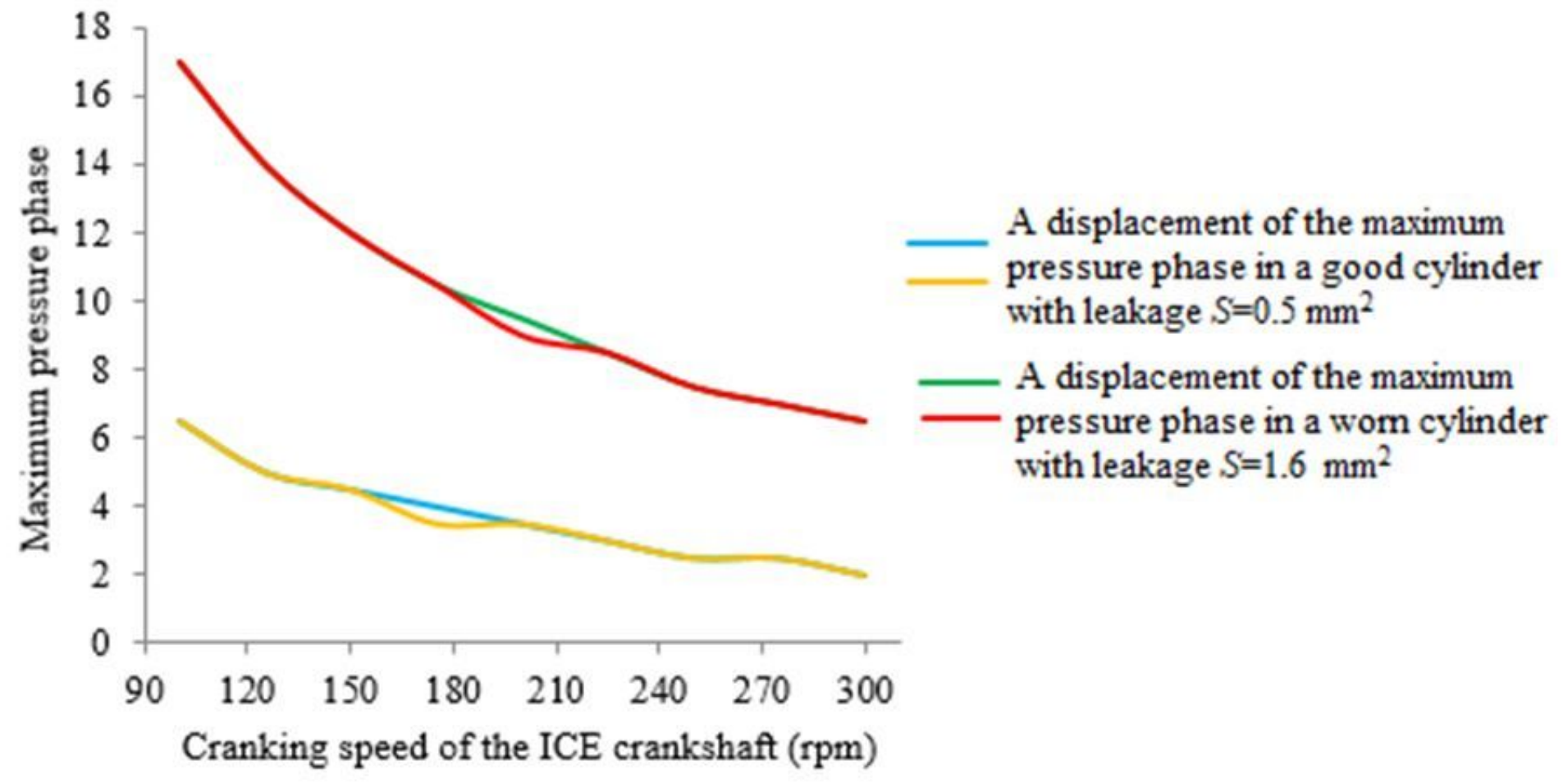

Figure 11

The dependence of the maximum pressure phase in the tested cylinders relative to the TDC when the piston rings are worn. 


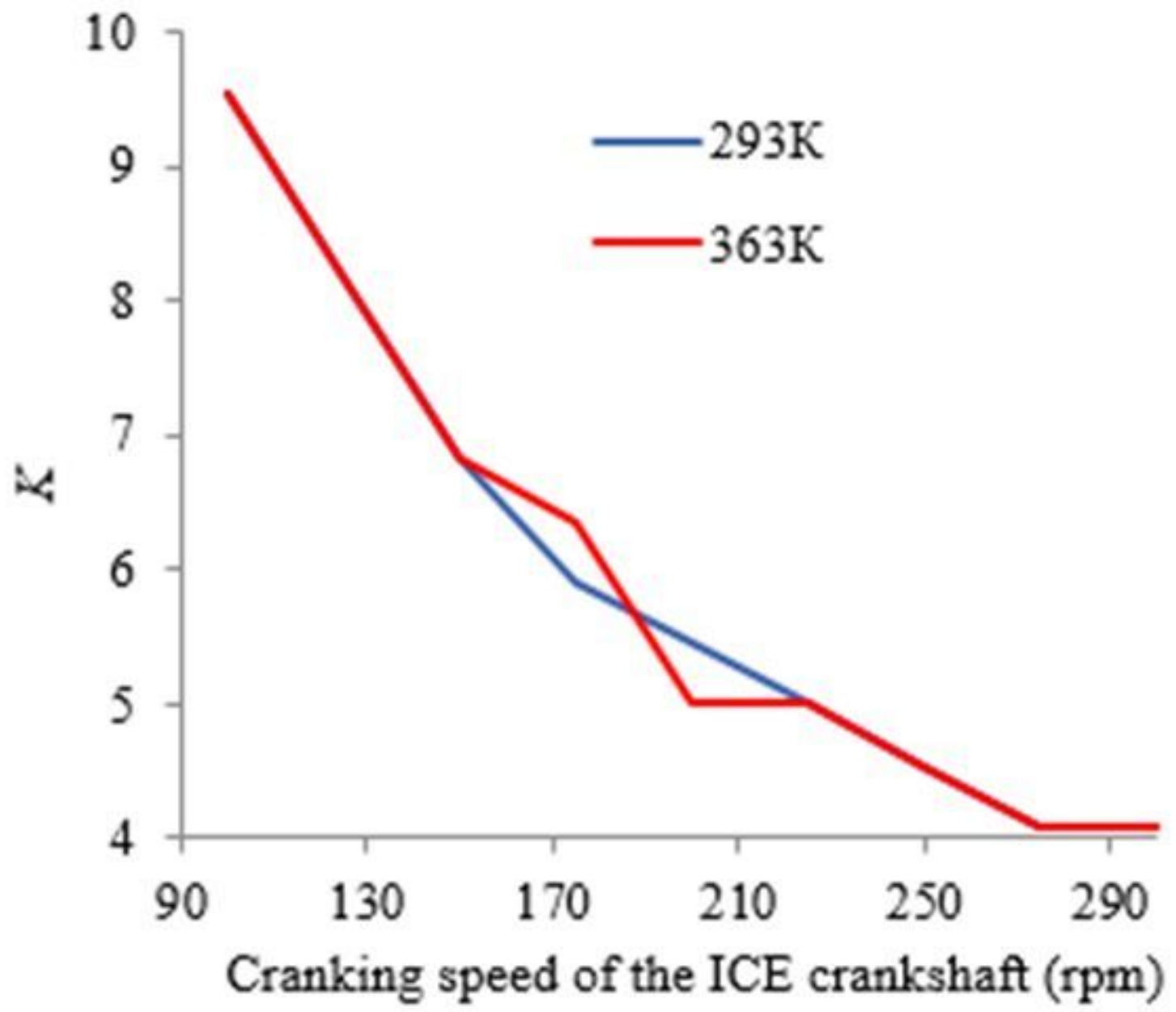

Figure 12

The dependence of the sensitivity coefficient of the phase displacement when the piston rings are worn, at the variation in the crankshaft speed. 